\title{
Effect of Warfarin on Survival in Scleroderma-associated Pulmonary Arterial Hypertension (SSc-PAH) and Idiopathic PAH. Belief Elicitation for Bayesian Priors
}

\author{
SINDHU R. JOHNSON, JOHN T. GRANTON, GEORGE A. TOMLINSON, HADDAS A. GROSBEIN, \\ GILLIAN A. HAWKER, and BRIAN M. FELDMAN
}

\begin{abstract}
Objective. Warfarin use in scleroderma (SSc)-associated pulmonary arterial hypertension (PAH) and idiopathic PAH (IPAH) is controversial. A prerequisite for a trial is the demonstration of community uncertainty. We evaluated experts' beliefs about the effect of warfarin on 3-year survival in SSc-PAH and IPAH, and factors that influence warfarin use.

Methods. PAH experts attending the 2008 American College of Rheumatology or American Thoracic Society meetings expressed the probability of 3-year survival without and with warfarin and their degree of uncertainty by applying adhesive dots, each representing a 5\% weight of probability, in "bins" on a line, creating a prior probability distribution or prior. Using a numeric rating scale, participants rated factors that influence their use of warfarin.

Results. Forty-five experts (44\% pulmonologists, 38\% rheumatologists, $16 \%$ cardiologists, $2 \%$ internists) underwent the belief elicitation interview. In SSc-PAH, the mean probabilities of 3-year survival without and with warfarin were $54 \%$ and $56 \%$, respectively. Pessimistic experts believe that warfarin worsens survival by $7 \%$. Optimistic experts believe that warfarin improves survival by $13 \%$. In IPAH, the mean probabilities of 3-year survival without and with warfarin were $68 \%$ and $76 \%$. Factors (mean rating out of $10,0=$ not at all important, $10=$ extremely important) that influence experts' use of warfarin were functional class (5.4), age (5.4), pulmonary artery pressure (5.2), peripheral vascular disease (3.6), disease duration (2.8), and sex (1.7).

Conclusion. Bayesian priors effectively quantify and illustrate experts' beliefs about the effect of warfarin on survival in SSc-PAH and IPAH. This study demonstrates the presence of uncertainty about the effect of warfarin, and provides justification for a clinical trial. (First Release Dec 15 2010; J Rheumatol 2011;38:462-9; doi:10.3899/jrheum.100632)
\end{abstract}

Key Indexing Terms:

BAYESIAN PRIORS

PULMONARY HYPERTENSION

SCLERODERMA MARFARIN

Pulmonary arterial hypertension (PAH) is a lethal disease characterized by elevated pulmonary artery pressures and progressive right heart failure. It is the leading cause of death in patients with systemic sclerosis (scleroderma, $\mathrm{SSc})^{1}$. Historically, patients with SSc-PAH have a 3-year

From the Division of Rheumatology, Division of Respirology, and Division of Critical Care Medicine, Department of Medicine, University Health Network; Department of Health Policy, Management and Evaluation, University of Toronto; Dalla Lana School of Public Health, University of Toronto; Division of Clinical Decision Making and Health Care, Toronto General Research Institute; Division of Rheumatology, Department of Paediatrics, The Hospital for Sick Children; and Division of Rheumatology, Department of Medicine, Women's College Hospital, Toronto, Ontario, Canada.

Supported by an operating grant from the Canadian Institutes of Health Research. Dr. S. Johnson has been awarded a Canadian Institutes of Health Research Clinician Scientist Award, Abbott Scholar Award in Rheumatology Research, and the Norton-Evans Fund for Scleroderma Research. Dr. G. Hawker is supported as the F.M. Hill Chair in Academic Women's Medicine, and a Distinguished Senior Rheumatologist

Researcher of The Arthritis Society, University of Toronto. Dr. B. Feldman holds a Canada Research Chair in Childhood Arthritis.

S.R. Johnson, MD, Division of Rheumatology, Department of Medicine, University Health Network, Department of Health Policy, Management survival of $22 \%-30 \%$, 2 . Patients with idiopathic $\mathrm{PAH}$ (IPAH) have a similarly poor prognosis, with a median survival time of 2.8 years ${ }^{4}$. One inexpensive and readily available potential treatment is warfarin. Clinical practice guidelines endorsed by medical professional organizations and

and Evaluation, University of Toronto; J.T. Granton, MD, Divisions of Respirology and Critical Care Medicine, Department of Medicine, University Health Network; G.A. Tomlinson, PhD, Department of Health Policy, Management and Evaluation and Dalla Lana School of Public Health, University of Toronto, Division of Clinical Decision Making and Health Care, Toronto General Research Institute; H.A. Grosbein, BSc, Division of Rheumatology, Department of Paediatrics, The Hospital for Sick Children; G.A. Hawker, MD, MSc, Department of Health Policy, Management and Evaluation, University of Toronto, Division of Rheumatology, Department of Medicine, Women's College Hospital; B.M. Feldman, MD, MSc, Department of Health Policy, Management and Evaluation and Dalla Lana School of Public Health, University of Toronto, Division of Rheumatology, Department of Paediatrics, The Hospital for Sick Children.

Full Release Article. For details see Reprints/Permissions at jrheum.org Address correspondence to Dr. S. Johnson, Division of Rheumatology, Toronto Western Hospital, 399 Bathurst Street, Toronto, Ontario M5T 2S8, Canada.E-mail: Sindhu.Johnson@uhn.on.ca Accepted for publication October 14, 2010. Personal non-commercial use only. The Journal of Rheumatology Copyright (c) 2011. All rights reserved. 
expert panels of PAH opinion leaders have recommended anticoagulation of patients with $\mathrm{PAH}$, with the rationale that PAH is partly the result of in situ thrombosis and abnormalities in the coagulation cascade ${ }^{5,6}$. However, our systematic review of the literature found that the evidence to support this recommendation is only modest; prior studies are limited by methodological constraints, which have led to conflicting results ${ }^{7}$. Five studies support the use of warfarin in IPAH $^{8,9,10,11,12}$, while 2 studies do not ${ }^{13,14}$. The major threat to the validity of the results of these studies is selection bias, as none of these were randomized trials. In addition, these studies were limited by small sample sizes, and thus the negative results may reflect insufficient power ${ }^{7}$. The role of warfarin in the treatment of SSc-PAH has not been established. There are no studies evaluating the effect of warfarin in SSc-PAH. Recommendations for the use of warfarin in SSc-PAH have been generalized from IPAH studies.

Attempts to conduct a randomized trial to definitively evaluate if warfarin confers survival benefit in these patients have met several challenges. First, the successful study of uncommon diseases, such as SSc-PAH and IPAH, is limited by the rarity of the condition. As a result, well designed studies are often labelled "negative" due to the inability to recruit sufficient numbers of patients ${ }^{15}$. Second, a necessary prerequisite for the conduct of a trial is demonstration of community uncertainty (a situation where not all within the community of experts agree on the efficacy of an intervention) ${ }^{16}$. During our group's attempt to conduct a warfarin trial, many centers were reluctant to recruit patients, as investigators believed that it is inappropriate to expose these patients to warfarin, while other investigators believed it is inappropriate to withhold warfarin from these patients (personal communication, J.T. Granton, Canadian Pulmonary Hypertension Trials Network Meeting, 2004).

A scientifically valid, quantitative demonstration of community uncertainty is needed to convince participating centers. Third, studies are often too small to allow adjustment for important confounding variables. Particularly in the setting of an observational study, factors that may influence a clinician's use of warfarin should be accounted for at the analytic stage. It has been suggested that selection of variables for a regression model (i.e., a model predicting the probability of exposure or estimating a treatment effect on the outcome) should be based on a priori knowledge ${ }^{17,18}$. Thus, explicit identification of factors that influence clinicians' use of warfarin in SSc-PAH and IPAH would inform study design and analysis.

A solution to address some of these issues is the use of innovative analytic methods, including Bayesian statistical models ${ }^{19}$. Application of Bayesian inference has great utility in the study of uncommon diseases. One of its advantages is the ability to incorporate prior evidence, including experts' beliefs about the effect of an intervention, in models estimating treatment effect ${ }^{20}$. Clinicians often rely on experts to guide clinical practice, particularly in the absence of definitive trial data. The Bayesian paradigm explicitly allows inclusion of experts' beliefs about the effect of an intervention by expressing these beliefs as prior probability distributions, or "priors"21. Expression of experts' beliefs as Bayesian priors has a number of pragmatic applications. First, Bayesian priors can demonstrate the presence of uncertainty (if it exists) in a quantifiable and illustrative manner. Second, quantification of beliefs allows determination of the magnitude of a treatment effect expected by experts. This information can be used to inform study design (e.g., sample size calculation ${ }^{22}$ and interim analysis ${ }^{23}$ ). Bayesian priors obtained through the elicitation of experts' beliefs can be used to augment scarce therapeutic data ${ }^{24}$.

The aim of our study was to evaluate experts' beliefs about the effect of warfarin on survival in SSc-PAH and IPAH. The primary objective of the study was to evaluate experts' beliefs about the effect of warfarin on 3-year survival in SSc-PAH and IPAH, expressed as probability distributions (i.e., expressed in a form that may be used as Bayesian priors). Secondary objectives of this study were to determine the degree of uncertainty regarding the effect of warfarin on 3-year survival in SSc-PAH and IPAH; and to evaluate factors that may influence experts' use of warfarin in patients with PAH.

\section{MATERIALS AND METHODS}

Study sample. Our review of belief elicitation methods for Bayesian priors had found that the most valid and reliable beliefs are obtained from individuals who have a greater depth of knowledge and experience in the $\operatorname{area}^{25}$. Thus, we elicited beliefs from experts in SSc-PAH and/or IPAH. Experts in SSc-PAH and/or IPAH were defined as members of (1) the Pulmonary Hypertension Association Scientific Leadership Council (PHA-SLC; n = 26); (2) Pulmonary Vascular Research Institute (PVRI) Council of Senior Fellows $(n=24)$; (3) Scleroderma Clinical Trials Consortium PH investigators $(n=23)$; and (4) Canadian Pulmonary Hypertension Trials Network $(\mathrm{CPHTN})(\mathrm{n}=23)$. These groups comprise individuals with clinical and/or research interests in PAH. Since elicitation is best conducted as a face-to-face interaction between the expert and the investigator ${ }^{24}$, we considered experts attending the 2008 American College of Rheumatology (ACR; San Francisco, CA, USA) or American Thoracic Society (ATS; Toronto, Canada) scientific meetings to be eligible for the study. Inclusion criteria were (1) membership in PHA-SLC, PVRI Council of Senior Fellows, SCTC PH Investigators, or CPHTN; (2) attendance at either the 2008 ACR or ATS meetings; (3) agreement to participate; and (4) a practice in which the expert cares for patients with SSc-PAH or IPAH. There is no consensus on the sample size required for an elicitation study 25 . Using the central limit theorem, a sample size of 30 was chosen to allow us to assume a normal distribution to the mean values of the group's belief ${ }^{26}$.

Recruitment. A letter was sent by e-mail/fax to members of all organizations inviting them to share their beliefs about warfarin use in PAH and asking if they would be attending the ATS or ACR meetings. Two weeks later, a second e-mail, letter, and fax were sent inviting them to participate. Among those who agreed to participate, an interview time was arranged. Characteristics of participants collected at the time of the interview included sex, specialty, years in practice treating $\mathrm{PAH}$ patients, type of practice, number of new SSc-PAH and/or IPAH patients seen per year, history of formal statistical training, and use of warfarin in their practice.

Elicitation interview. A 10-minute belief elicitation interview was conductPersonal non-commercial use only. The Journal of Rheumatology Copyright (c) 2011. All rights reserved. 
ed with each expert. Participants were given a sample questionnaire to illustrate the belief elicitation method ${ }^{27}$. The sample questionnaire was identical to the study questionnaire but used vitamin $\mathrm{C}$ as the therapeutic intervention. Participants were given the opportunity to ask questions about sample questionnaire questions and response options.

Study questionnaire. The investigator read each question aloud. Participants were asked, for an average group of newly diagnosed SSc-PAH patients (and separately, for an average group of IPAH patients) to specify the probability of being alive at 3 years among patients if: (1) not treated with warfarin and (2) treated with warfarin. They were asked to indicate their response by placing an "X" on a line with $5 \%$ probability intervals ranging from $0 \%$ to $100 \%$. Participants were asked to express the uncertainty around their estimate of survival among warfarin-treated patients by placing an " $\mathrm{X}$ " at the upper and lower limit of their estimate. Participants were asked to indicate the weight of their belief for the probability of 3-year survival among warfarin-treated patients by placing circular adhesive dots of $0.64-\mathrm{cm}$ diameter, each representing $5 \%$ probability, in discrete interval "bins." Participants were given 20 dots summing to $100 \%$ probability. The investigator placed one dot in each bin based on the upper and lower boundaries indicated by the participant to reduce the risk of error. The investigator verified with the participant if the placement of dots was correct. The participant was asked to place the remaining 18 dots to indicate their weight of belief. Participants were asked to review the shape and distribution of dot placement, and asked to verify if it reflected their belief about the effect of warfarin on survival. Participants were given the opportunity to revise their placement of dots until they felt it reflected their belief. Finally, participants were asked to categorize their belief about the overall effect of warfarin using the response options "improves survival," "worsens survival," or "no effect on survival." The questionnaire was laminated so that the dots could be easily removed if a participant wished to revise their response. Upon completion, the questionnaire was relaminated to prevent movement of the dots. This elicitation procedure has a median time to completion of 10 minutes, with demonstrable face validity, construct validity, and reliability 27 .

Factors influencing use of warfarin. Experts were asked to list and evaluate factors that influence their decision to use warfarin in patients with SSc-PAH and IPAH. The importance of functional class, age, pulmonary artery pressure, peripheral vascular disease, $\mathrm{PAH}$ disease duration since diagnosis, interstitial lung disease, and sex was specifically elicited as these were prognostic factors in the published literature ${ }^{3,28}$. Importance was reported using a numeric rating scale, where 0 indicated not at all important and 10 extremely important.

Analysis. Sample. Descriptive statistics were used to summarize participant characteristics and relative importance of factors that influence their use of warfarin.

Priors. Individual histograms representing the prior beliefs about the effect of warfarin for each respondent were constructed by counting the number of $5 \%$ dots in each bin. A "group" prior probability distribution representing the entire group of respondents was constructed by averaging the adhesive dot counts in each bin across all respondents. A "pessimistic" prior was constructed using information from the lower tenth percentile of participants specifying the smallest treatment effect. An "optimistic" prior was constructed using information from the upper tenth percentile of participants specifying the largest average treatment effect. For each participant, the risk difference (treatment effect) was determined by subtracting their reported probability of survival when treated without warfarin from their reported probability treated with warfarin. A prior probability distribution for the risk difference was constructed for each expert. The weights assigned to the probability of survival treated with warfarin were centered at their reported risk difference.

Comparison with the literature. A systematic review of the literature had been previously performed (and repeated to identify additional studies published between 2006 and 2010) to identify studies evaluating the use of warfarin in $\mathrm{SSc}-\mathrm{PAH}$ or $\mathrm{IPAH}^{7}$. Eligible studies were observational studies and randomized trials that reported death as an outcome. Studies were identified using Medline and Embase databases. Two reviewers independently abstracted study design, sample size, treatment, and 3-year mortality data onto standard forms. Details of the systematic review are available ${ }^{7}$. Four observational studies reporting the effect of warfarin on 3-year survival in IPAH were identified $9,11,12,14$, and were aggregated in a Bayesian metaanalysis. The absolute risk difference (the difference in the proportion of events observed in the patients who did and those who did not receive warfarin) was calculated ${ }^{29}$. A random-effects model was constructed (allowing each study to have its own true risk difference); and a uniform prior in the range -1 to 1 (i.e., $-100 \%$ to $100 \%$ ) was given to the population absolute risk difference, giving equal weight to all possible values of the variable ${ }^{29}$. The mean absolute risk difference and $95 \%$ credible interval $(\mathrm{CrI})$ were calculated

Factors influencing use of warfarin. The mean importance and standard deviation for each factor were calculated. A Bayesian multivariable normal model was constructed for the logits of the importance scores for the 6 factors (rescaled between 0 and 1). Markov chain Monte Carlo (MCMC) samples from the posterior distribution of the mean logits were used to produce rankings, indicating the relative importance of each factor, $95 \% \mathrm{CrI}$, and the probability of each factor having the highest ranking.

Bayesian analyses. Our analysis used MCMC to sample from the posterior distribution of variables. Starting at 3 randomly generated initial values, the chains were run for a 5,000 iteration "burn-in" period, in which the chain moved from these starting values toward the correct posterior distribution. We used the Brooks-Gelman-Rubin statistic to verify convergence at this point, that is, that all 3 chains were sampling the same distribution of values. Then 10,000 new sampled values were collected and used to estimate properties of the posterior distribution - means, medians, odds ratios (OR), 95\% CrI, and probabilities. The reporting of the analysis and results is in accord with the ROBUST criteria ${ }^{30}$. The code for all analyses is available from the authors upon request. Analyses were performed using SAS (version 9.2; SAS Institute, Cary, NC, USA), R (version 2.2.1; R Foundation for Statistical Computing ${ }^{31}$ ), and WinBUGS (version 1.4.3; Imperial College and Medical Research Council, London, $\mathrm{UK}^{32}$ ).

Research ethics board approval was obtained before the study. Implicit consent was given when the participants agreed to proceed with the elicitation interview.

\section{RESULTS}

Sample. The combined membership list comprised 95 potential study participants. However, 42 individuals did not fulfil study eligibility criteria (4 did not care for adult patients with SSc-PAH or IPAH, 21 declined or did not respond to our invitations to participate (reason not given), and 17 indicated that they would not attend either scientific meeting). Fifty-three experts fulfilled all eligibility criteria. We were unable to arrange a meeting time with 8 experts. We were able to conduct belief elicitation interviews with 45 experts (Figure 1). Participant characteristics are summarized in Table 1.

Warfarin use. Thirty-eight (84\%) participants use warfarin in their practice to treat patients with SSc-PAH or IPAH. The frequency of warfarin use ranged from "only rarely" to "always, unless contraindicated." A distinction in warfarin use between SSc-PAH and IPAH was not made in the questionnaire. A greater proportion of males, 34/38 (89\%), reported use of warfarin compared to females, 4/7 (57\%), giving a median $\mathrm{OR}=0.2(95 \% \mathrm{CrI} 0.03,0.91)$. There was no difference in the frequency of warfarin use between prac- 


\section{5 potential participants}

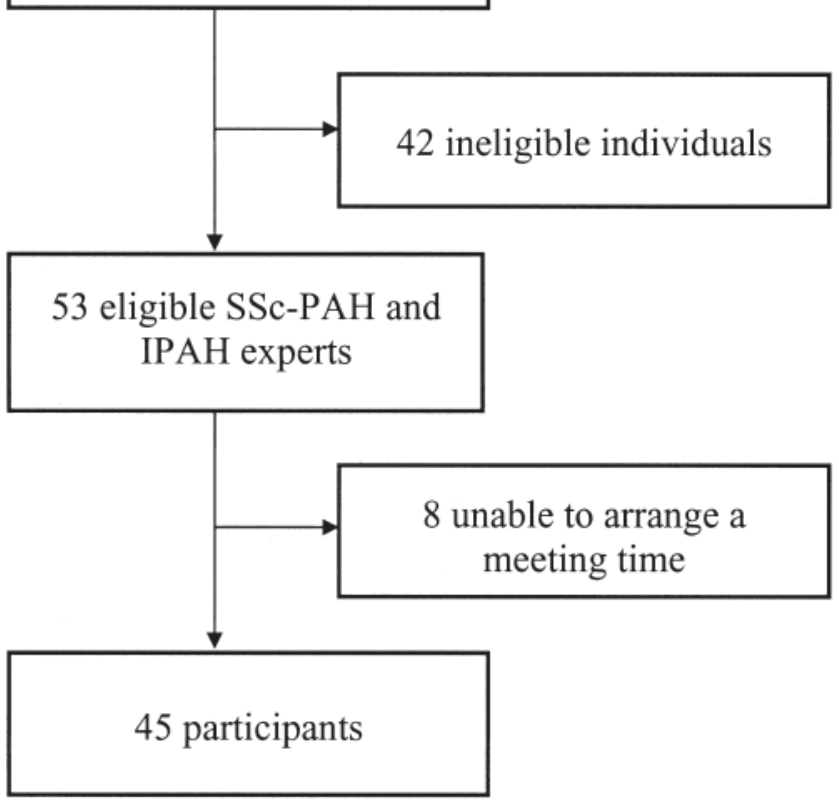

Figure 1. The process of participant recruitment. SSc-PAH: scleroderma-associated pulmonary arterial hypertension; IPAH: idiopathic PAH.

Table 1. Characteristics of study participants.

\begin{tabular}{lc}
\hline Characteristics & No. $(\%), \mathrm{n}=45$ \\
\hline Male sex & $38(84)$ \\
Specialty & $7(16)$ \\
$\quad$ Cardiology & $20(44)$ \\
Pulmonology & $17(38)$ \\
$\quad$ Rheumatology & $1(2)$ \\
$\quad$ Internal medicine & \\
No. years seeing patients with pulmonary arterial & $15(10-25)$ \\
$\quad$ hypertension (PAH), median (25\%-75\%) & \\
Type of practice (\%) & $0(0)$ \\
$\quad$ Nonteaching hospital & $44(98)$ \\
$\quad$ Teaching hospital & $1(2)$ \\
$\quad$ Both & $30(15-50)$ \\
No. new SSc-PAH and/or IPAH patients per year, \\
$\quad$ median (25\%-75\%) \\
Location of practice \\
$\quad$ Europe \\
$\quad$ North America \\
History of postsecondary statistical training \\
Use of warfarin in their patients with pulmonary \\
$\quad$ hypertension
\end{tabular}

SSc: systemic sclerosis; IPAH: idiopathic pulmonary arterial hypertension.

tices based in Europe [7/8 (88\%)] and North America [31/37 (84\%)], median OR 0.96 (95\% CrI 0.17, 8.7). Rheumatologists [10/17 (59\%)] less frequently reported use of warfarin to treat PAH patients, compared to cardiologists/pulmonologists [27/27 (100\%)].
Experts' beliefs about warfarin in SSc-PAH. The mean (SD) probability of 3-year survival without warfarin was 54\% $(16 \%)$ and with warfarin $56 \%(16 \%)$. There were no differences in the probabilities of survival in SSc-PAH patients across specialties, practice locations, or sexes. The group prior probability distribution for 3-year survival in patients treated with warfarin is presented in Figure 2. The curve is slightly left-skewed and bimodal.

Pessimistic experts $(n=5)$ believe that warfarin confers an absolute worsening in 3-year survival by a mean of $7 \%$. Optimistic experts $(n=5)$ believe warfarin confers an absolute improvement in survival by a mean of $13 \%$ (Figure $3)$. Comparing pessimists to optimists, there were no differences in sex (males: $3 / 5$ vs $3 / 5$, respectively) or practice location (North America: 5/5 vs 4/5). SSc-PAH optimists see more new consults per year than pessimists (54 vs 33, respectively). SSc-PAH pessimists have been in practice a mean of 14 years and optimists a mean of 17 years. All SSc-PAH pessimists $(5 / 5)$ report use of warfarin in their PAH practice, whereas 3/5 SSc-PAH optimists report use of warfarin.

Experts' beliefs about warfarin in IPAH. In patients with IPAH, the mean (SD) probability of 3-year survival without warfarin was $68 \%(12 \%)$ and with warfarin was $76 \%(11 \%)$. There were no significant differences in the probability of survival with and without warfarin in IPAH patients across specialties, practice locations, or sexes. The group prior probability distribution for 3-year survival in patients treated with warfarin is presented in Figure 2; the curve is left-skewed. The height of the curve at an $\mathrm{x}$-axis value is proportional to the experts' belief about how likely that value is.

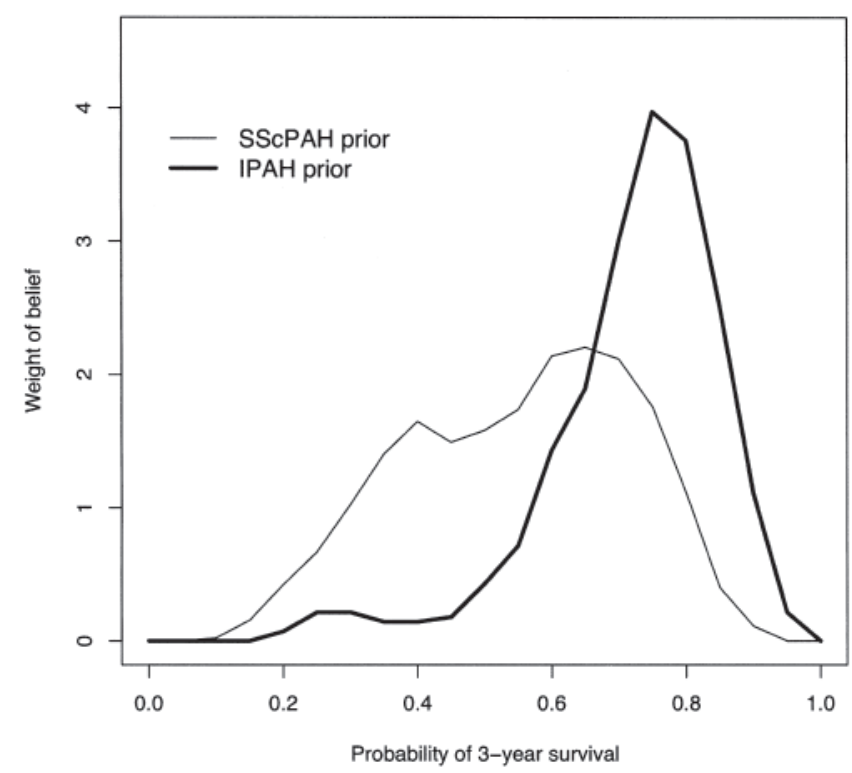

Figure 2. Group prior probability distributions for probability of 3-year survival in patients with SSc-PAH or IPAH treated with warfarin. 


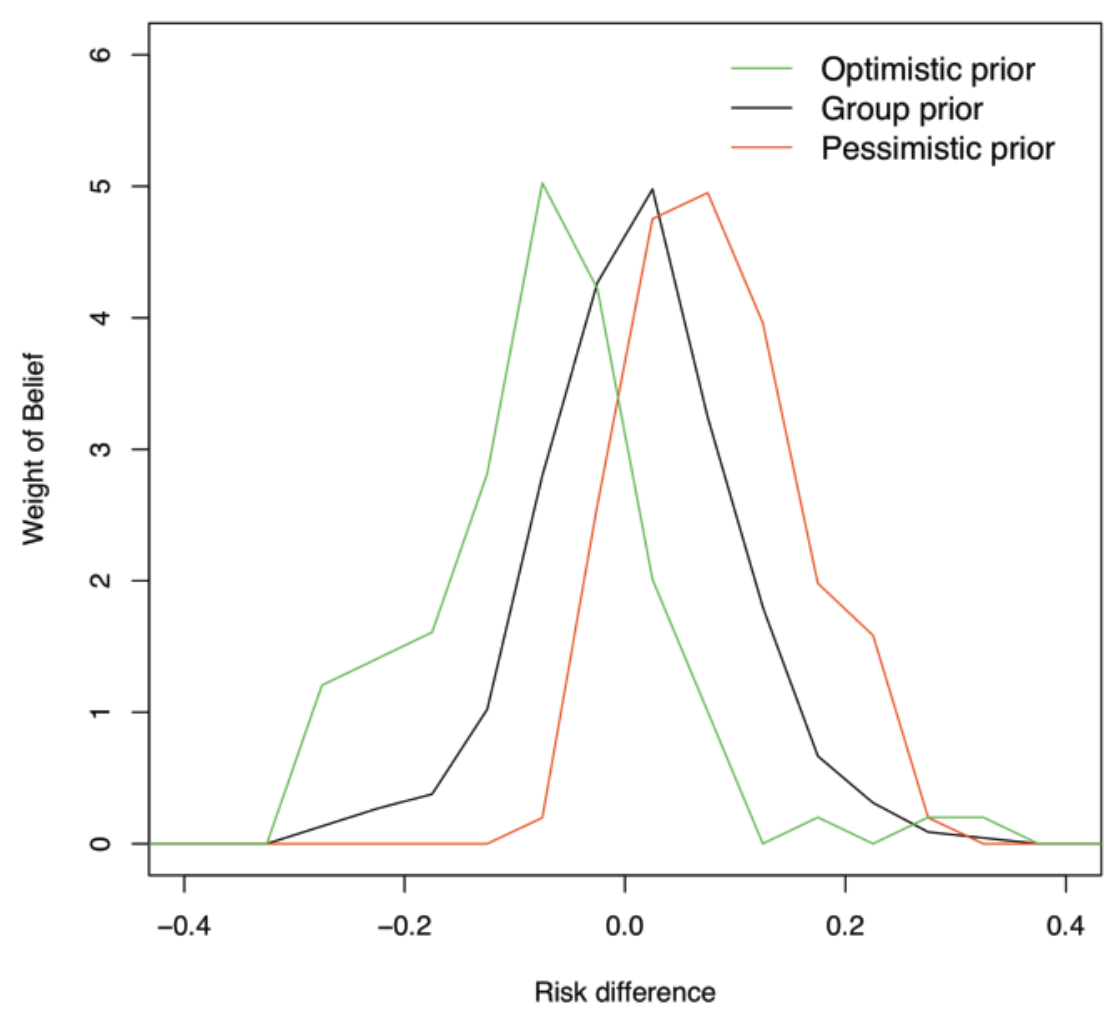

Figure 3. Prior probability distributions for the effect of warfarin on the absolute risk difference for 3-year mortality in patients with SSc-PAH from experts. Values $>$ 0 indicate warfarin increases risk of death; values $<0$ indicate warfarin reduces risk of death.

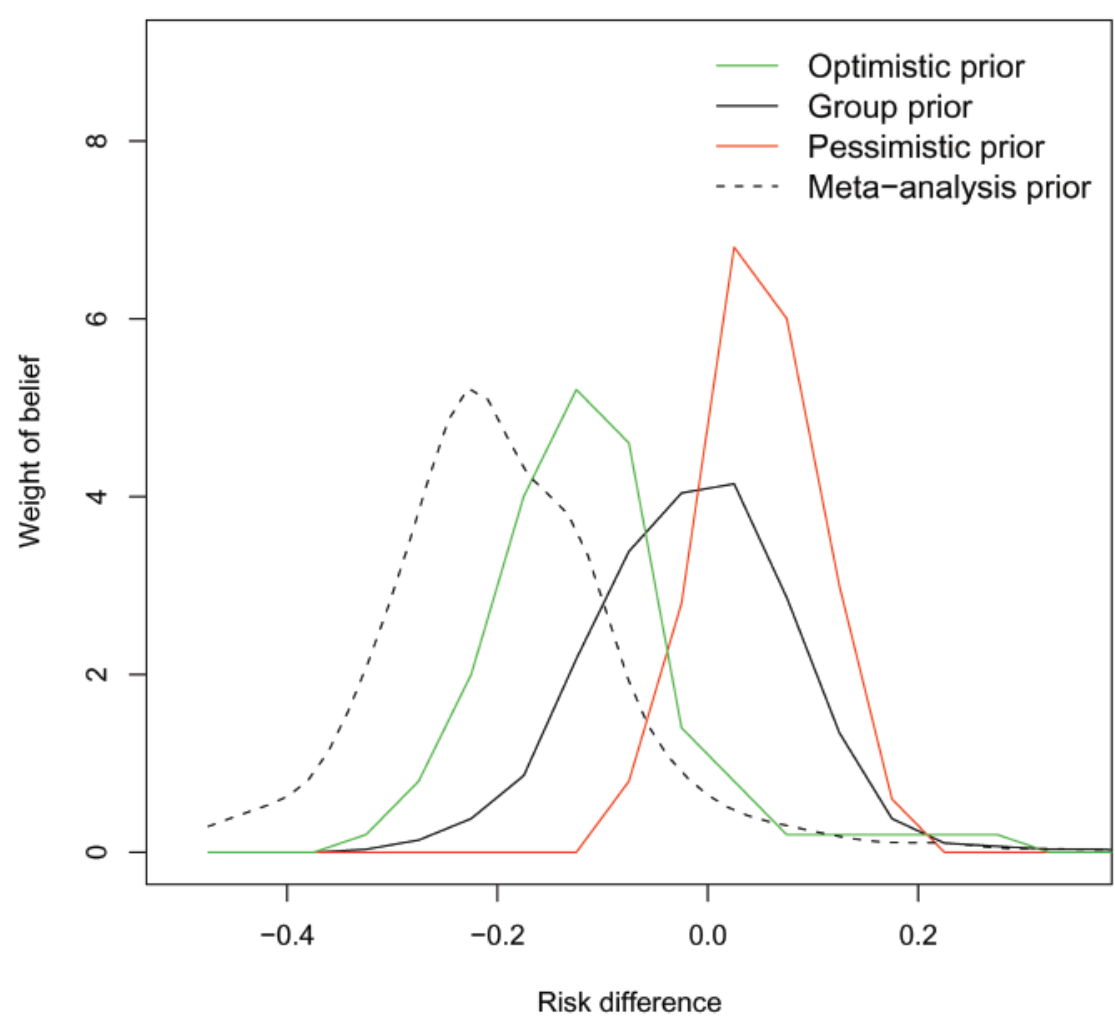

Figure 4. Probability distributions for the effect of warfarin on the absolute risk difference for 3-year mortality in patients with IPAH from experts and the published literature. Values $>0$ indicate warfarin increases risk of death; values $<0$ indicate warfarin reduces risk of death. 
Pessimistic experts believe warfarin had no effect on survival, with a mean of $0 \%$. Optimistic experts believe warfarin improves survival, by a mean of $17 \%$ (Figure 4). Comparing pessimists to optimists, there were no differences in sex (males: $5 / 5$ vs $4 / 5$, respectively) or practice location (North America: 3/5 vs 5/5). The numbers of years in practice for IPAH pessimists and optimists were $19 \mathrm{com}$ pared to 18 years. The mean numbers of new consults per year for IPAH pessimists and optimists were 185 versus 66 . All IPAH pessimists (5/5) and optimists (5/5) reported use of warfarin in their PAH practice.

Factors that influence use of warfarin. The importance and ranking of factors that influence use of warfarin are reported in Table 2. Participants identified additional factors that influence their use of warfarin in SSc-PAH and IPAH. Factors related to the right heart [right heart failure $(n=8)$, right heart function $(n=3)$ ], thrombophilic state [history of thromboembolic disease $(n=7)$, antiphospholipid antibody $(n=4)$, hypercoagulable state $(n=2)]$, gastrointestinal disease [esophageal or gastric disease $(n=11)$, gastric antral vascular ectasia $(n=1)$ ], bleeding [history of gastrointestinal bleeding $(n=10)$, risk of bleeding $(n=6)$, thrombocytopenia $(n=2)$, menorrhagia $(n=1)$, hemoptysis $(n=1)$, epistaxis $(n=1)]$ were considered important. Additional factors included falls $(\mathrm{n}=7)$, compliance $(\mathrm{n}=5)$, atrial fibrillation $(\mathrm{n}=4)$, anemia $(\mathrm{n}=2)$, IPAH versus SSc-PAH $(\mathrm{n}=$ $2)$, cardiac output $(n=2)$, sedentary $(n=2)$, liver function $(n=1)$, central nervous system disease $(n=1)$, severity of scleroderma $(n=1)$, and patient risk tolerance $(n=1)$. A distinction was not made between SSc-PAH and IPAH.

Comparison of experts' beliefs with the published literature. Metaanalysis of 4 observational studies reporting the effect of warfarin on 3-year survival in IPAH found a $20 \%$ absolute reduction in mortality in patients who received warfarin $(95 \% \mathrm{CrI}-0.49,0.10)$. The probability distributions for the metaanalysis-derived absolute risk difference and experts-derived absolute risk difference are presented in Figure 4.

\section{DISCUSSION}

Use of a formal elicitation procedure allowed us to quantify, illustrate, and gain important insights into beliefs about the effect of warfarin held by leaders in the pulmonary hypertension community. Experts are guarded about the probability of survival with and without warfarin. The grim SSc-PAH prognosis is consistent with the published literature, which reports 2-year mortality estimates among warfarin-naive patients ranging from $22 \%$ to $47 \% \%^{2,3,33,34}$. There are no published estimates of SSc-PAH survival in warfarin-treated patients with which to compare our study findings. Among the experts in this study, there was a wide range of probability of survival, ranging from as low as $20 \%$ to as high as $80 \%$. This may reflect that SSc is a heterogeneous condition with different subsets of clinical presentation and progno$\mathrm{sis}^{35}$. Among patients with SSc-PAH, experts believe that warfarin confers a small improvement in the probability of 3year survival. Depending on the definition of a minimum clinically important difference, the magnitude of this effect may be interpreted by some as "no effect." However, it is important to note that some experts (pessimists) believe warfarin worsens survival (i.e., confers harm), while others (optimists) believe that warfarin improves survival. These widely disparate views demonstrate that there is a divergence of opinion within the expert community.

Insights are also gained by evaluation of experts' probability distributions among patients with IPAH. As a group, experts believe warfarin improves survival. The wide range in probability of survival (50\% to 90\%) suggests the presence of community uncertainty. Some (relatively pessimistic) experts believe warfarin has no effect on survival, while others believe warfarin improves survival considerably.

The experts' belief that warfarin improves survival in IPAH is consistent with the direction of treatment effect in our metaanalysis. This supports the external validity of our study findings. However, there is a discrepancy in the magnitude of the effect, where experts believe that warfarin confers a smaller improvement in survival than was demon-

Table 2. Factors that influence experts' use of warfarin. Importance was reported on a numeric analog scale, where 0 indicated not at all important and 10 extremely important.

\begin{tabular}{lccc}
\hline Factor $(\mathrm{n}=38)$ & $\begin{array}{c}\text { Mean Importance } \\
(\mathrm{SD})\end{array}$ & $\begin{array}{c}\text { Ranking* } \\
(95 \% \text { CrI })\end{array}$ & $\begin{array}{c}\text { Probability of Having } \\
\text { the Highest Ranking, \% }\end{array}$ \\
\hline NYHA/WHO functional class & $5.4(2.5)$ & $2(1,3)$ & 46 \\
Age & $5.4(2.3)$ & $2(1,3)$ & 36 \\
Degree of elevation of pulmonary artery pressure & $5.2(2.5)$ & $2(1,3)$ & 18 \\
Peripheral vascular disease & $3.6(2.7)$ & $4(4,5)$ & 0 \\
Pulmonary arterial hypertension disease duration & $2.8(2.5)$ & $5(5,5)$ & 0 \\
Interstitial lung disease & $2.3(2.1)$ & $6(5,7)$ & 0 \\
Sex & $1.7(2.0)$ & $7(6,7)$ & 0 \\
\hline
\end{tabular}

\footnotetext{
* Importance of factors affecting use of warfarin in patients with pulmonary arterial hypertension $(1=$ most important, 7 = least important). 95\% CrI: 95\% credible interval; NYHA/WHO: New York Heart Association/World Health Organization.
} 
strated in the metaanalysis. This discrepancy may be related to a few issues. First, the metaanalysis includes only studies that reported 3-year survival as an outcome. It was necessary to identify one common outcome on which to base the analysis, and compare the results with experts' beliefs. The experts are likely aware that the results of other studies (that reported other survival endpoints) were conflicting, some showing benefit and others showing no benefit. The studies are all challenged by "confounding by indication" and this may lead to biased results that overestimate the treatment effect; experts may adjust their own estimates of treatment effect to account for the perceived bias. Further, the more conservative belief in survival benefit held by experts may reflect their real-world experience. It may be that pessimism has come after experiences of unsuccessful use of warfarin. In evaluation of other medical interventions, the magnitude of a treatment effect in the real world is often smaller than that observed in a study ${ }^{36}$.

Identification of factors that should be controlled in an observational study is another important insight. Confounding by indication often affects the validity of observational study findings, and in particular, may have affected the results of previous IPAH warfarin studies. Thus, it is important to recognize factors that influence experts' use of warfarin. Interestingly, none of the factors had a high mean rating. However, we were able to rank them based on their relative importance. In studies with a small sample size and limited power to adjust for confounding, it is useful to know which factors should be included in models estimating the treatment effect.

Limitations to this study may be related to characteristics of the study participants. Since there is no formal definition for "PAH expert," we defined an expert as a physician who is a member of one of 4 pulmonary hypertension-related organizations. The large number of years in practice seeing patients with PAH, the large number of new consults per year (large for uncommon diseases), and the predominance of teaching hospital-based practice, support that the participants were indeed experts. This sample may not be representative of physicians in community-based, non-teaching hospital practices. Patient mix and clinical experience could be systematically different for physicians at teaching hospitals. Similarly, our data suggest that more male physicians use warfarin to treat PAH than female physicians. Given the small number of female physicians in this study, there is considerable uncertainty around the odds ratio, limiting our ability to make any strong inferences. A second potential limitation was the requirement for experts to attend one of 2 scientific meetings in order to be considered eligible for study. As a result, some experts were excluded from participation. Self-selection bias may have occurred as a result of experts not responding to our invitation to participate. This may have led to bias if they chose not to participate as a consequence of their views on anticoagulation in PAH.
Similarly, experts who attended the meetings may have been systematically different from those who did not. Our previous work on belief elicitation for Bayesian priors found that responses are more valid and reliable when elicited face-to-face. Conducting the interviews at the 2 largest scientific meetings (of different disciplines and held in different countries) where the experts were most likely to attend was the most pragmatic solution. This decision likely improved the internal validity of the results, with a small influence on the external validity.

We have demonstrated that this belief elicitation method can be effectively used to quantify and illustrate the beliefs held by experts regarding the effect of an intervention. This method is not limited to PAH, and can be generalized to the study of many uncommon diseases. Using the Bayesian inferential paradigm, elicited beliefs in the form of priors can be used to supplement limited therapeutic data ${ }^{24}$.

Further, our study is the first to evaluate the beliefs of experts about the effect of warfarin on survival in SSc-PAH and IPAH and the magnitude of this effect. Demonstration of a divergence of opinion regarding the effect of warfarin on survival in SSc-PAH and IPAH indicates the presence of community uncertainty. If warfarin is effective in improving survival, it is an inexpensive therapy that could be accessible globally. If ineffective for improving survival, the harm of major hemorrhage precludes its use in these patient groups. A randomized trial is needed to address this clinical question. Our study offers necessary data to provide justification for the trial and to inform trial design.

\section{ACKNOWLEDGMENT}

The authors thank the following individuals for assistance with this study: Dr. David Badesch, Dr. Robyn Barst, Dr. Raymond Benza, Dr. Todd Bull, Dr. Ghazwan Butrous, Dr. Richard Channick, Dr. Vladimir Contreas, Dr. Clive Davis, Dr. Peter Docherty, Dr. C. Gregory Elliott, Dr. Barri Fessler, Dr. Daniel Furst, Dr. Eric Hachulla, Dr. Paul Hassoun, Dr. Paul Hernandez, Dr. Nicholas Hill, Dr. Andrew Hirsch, Dr. Vivien Hsu, Dr. Marc Humbert, Dr. Shahin Jamal, Dr. Bashar Kahaleh, Dr. Wanruchada Katchamat, Dr. Dinesh Khanna, Dr. Neil Lazar, Dr. Peter Lee, Dr. Robert Levy, Dr. Dale Lien, Dr. James Loyd, Dr. Andrea H.L. Low, Dr. Jeffrey Mann, Dr. Maureen Mayes, Dr. Micheal McGoon, Dr. Thomas Medsger, Dr. Peter Merkel, Dr. Evangelos Mikalakis, Dr. Nicholas Morrell, Dr. Sanjay Mehta, Dr. David Ostrow, Dr. Ronald Oudiz, Dr. Janet Pope, Dr. Steve Provencher, Dr. Stuart Rich, Dr. Gabriela Riemekasten, Dr. Carine Salliot, Dr. James Seibold, Dr. Olivier Sitbon, Dr. Virginia Steen, Dr. John Swiston, Dr. John Thenganatt, Dr. Gabriele Valentini, Dr. Doug Veale, Dr. Fred Wigley, Dr. Duminda Wijeysundera, and Dr. Harindra Wijeysundera.

The authors thank the Scleroderma Clinical Trials Consortium, the Pulmonary Hypertension Association, the Pulmonary Vascular Research Institute, and the Canadian Pulmonary Hypertension Trials Network for assistance with the conduct of this study. The authors thank administrative staff of the American College of Rheumatology and the American Thoracic Society for assistance with logistical issues pertaining to the conduct of this study at their respective scientific meetings.

\section{REFERENCES}

1. Scussel-Lonzetti L, Joyal F, Raynauld JP, Roussin A, Rich E, Goulet JR, et al. Predicting mortality in systemic sclerosis: analysis of a cohort of 309 French Canadian patients with emphasis on 
features at diagnosis as predictive factors for survival. Medicine (Baltimore) 2002;81:154-67.

2. Koh ET, Lee P, Gladman DD, Abu-Shakra M. Pulmonary hypertension in systemic sclerosis: an analysis of 17 patients. $\mathrm{Br}$ J Rheumatol 1996;35:989-93.

3. Williams MH, Das C, Handler CE, Akram MR, Davar J, Denton $\mathrm{CP}$, et al. Systemic sclerosis associated pulmonary hypertension: improved survival in the current era. Heart 2006;92:926-32.

4. D'Alonzo GE, Barst RJ, Ayres SM, Bergofsky EH, Brundage BH, Detre KM, et al. Survival in patients with primary pulmonary hypertension. Results from a national prospective registry. Ann Intern Med 1991;115:343-9.

5. Welsh CH, Hassell KL, Badesch DB, Kressin DC, Marlar RA. Coagulation and fibrinolytic profiles in patients with severe pulmonary hypertension. Chest 1996;110:710-7.

6. Johnson SR, Granton JT, Mehta S. Thrombotic arteriopathy and anticoagulation in pulmonary hypertension. Chest 2006;130:545-52.

7. Johnson SR, Mehta S, Granton JT. Anticoagulation in pulmonary arterial hypertension: a qualitative systematic review. Eur Respir J 2006;28:999-1004.

8. Roman A, Rodes-Cabau J, Lara B, Bravo C, Monforte V, Pallissa E, et al. [Clinico-hemodynamic study and treatment of 44 patients with primary pulmonary hypertension]. Med Clin (Barc) 2002;118:761-6.

9. Fuster V, Steele PM, Edwards WD, Gersh BJ, McGoon MD, Frye RL. Primary pulmonary hypertension: natural history and the importance of thrombosis. Circulation 1984;70:580-7.

10. Kawut SM, Horn EM, Berekashvili KK, Garofano RP, Goldsmith RL, Widlitz AC, et al. New predictors of outcome in idiopathic pulmonary arterial hypertension. Am J Cardiol 2005;95:199-203.

11. Rich S, Kaufmann E, Levy PS. The effect of high doses of calcium-channel blockers on survival in primary pulmonary hypertension. N Engl J Med 1992;327:76-81.

12. Ogata M, Ohe M, Shirato K, Takishima T. Effects of a combination therapy of anticoagulant and vasodilator on the long-term prognosis of primary pulmonary hypertension. Jpn Circ J 1993;57:63-9.

13. Storstein O, Efskind L, Muller C, Rokseth R, Sander S. Primary pulmonary hypertension with emphasis on its etiology and treatment. Acta Med Scand 1966;179:197-212.

14. Frank H, Mlczoch J, Huber K, Schuster E, Gurtner HP, Kneussl M. The effect of anticoagulant therapy in primary and anorectic drug-induced pulmonary hypertension. Chest 1997;112:714-21.

15. Johnson SR, Feldman BM, Pope JE, Tomlinson GA. Shifting our thinking about uncommon disease trials: the case of methotrexate in scleroderma. J Rheumatol 2009;36:323-9.

16. Gifford F. Uncertainty about clinical equipoise. Clinical equipoise and the uncertainty principles both require further scrutiny. BMJ 2001;322:795.

17. Senn S. Testing for baseline balance in clinical trials. Stat Med $1994 ; 13: 1715-26$
18. Austin PC. Propensity-score matching in the cardiovascular surgery literature from 2004 to 2006: a systematic review and suggestions for improvement. J Thorac Cardiovasc Surg 2007;134:1128-35.

19. Austin PC, Brunner LJ, Hux JE. Bayeswatch: an overview of Bayesian statistics. J Eval Clin Pract 2002;8:277-86.

20. Chaloner K. Elicitation of prior distributions. In: Berry DA, Stangl DK, editors. Bayesian biostatistics. New York: Marcel Dekker Inc.; 1996:141-56.

21. Chaloner K, Rhame FS. Quantifying and documenting prior beliefs in clinical trials. Stat Med 2001;4:581-600.

22. Spiegelhalter DJ, Freedman LS. A predictive approach to selecting the size of a clinical trial, based on subjective clinical opinion. Stat Med 1986;5:1-13.

23. Spiegelhalter DJ. Incorporating Bayesian ideas into health-care evaluation. Statist Sci 2004;19:156-74.

24. O'Hagan A, Buck CE, Daneshkhah A, Eiser JR, Garthwaite PH, Jenkinson DJ, et al. Uncertain judgements. Eliciting experts' probabilities. Chichester: John Wiley \& Sons Ltd.; 2006.

25. Johnson SR, Tomlinson GA, Hawker GA, Granton JT, Feldman BM. Methods to elicit beliefs for Bayesian priors: a systematic review. J Clin Epidemiol 2010;63:355-69.

26. Norman GR, Streiner DL. Biostatistics. The bare essentials. 3rd ed. Hamilton: BC Decker; 2008.

27. Johnson SR, Tomlinson GA, Hawker GA, Granton JT, Grosbein HA, Feldman BM. A valid and reliable belief elicitation method for Bayesian priors. J Clin Epidemiol 2010;63:370-83.

28. Johnson SR, Swiston JR, Granton JT. Prognostic factors for survival in scleroderma associated pulmonary arterial hypertension. J Rheumatol 2008;35:1584-90.

29. Warn DE, Thompson SG, Spiegelhalter DJ. Bayesian random effects meta-analysis of trials with binary outcomes: methods for the absolute risk difference and relative risk scales. Stat Med 2002;21:1601-23

30. Sung L, Hayden J, Greenberg ML, Koren G, Feldman BM, Tomlinson GA. Seven items were identified for inclusion when reporting a Bayesian analysis of a clinical study. J Clin Epidemiol 2005;58:261-8

31. R Development Core Team. R: A language and environment for statistical computing. Vienna: R Foundation for Statistical Computing; 2005.

32. Lunn DJ, Thomas A, Best N, Spiegelhalter D. WinBUGS - a Bayesian modelling framework: concepts, structure, and extensibility. Statist Comput 2000;10:325-37.

33. Steen V, Medsger TA Jr. Predictors of isolated pulmonary hypertension in patients with systemic sclerosis and limited cutaneous involvement. Arthritis Rheum 2003;48:516-22.

34. Mukerjee D, St. George D, Coleiro B, Knight C, Denton CP, Davar $\mathrm{J}$, et al. Prevalence and outcome in systemic sclerosis associated pulmonary arterial hypertension: application of a registry approach. Ann Rheum Dis 2003;62:1088-93.

35. Johnson SR, Feldman BM, Hawker GA. Classification criteria for systemic sclerosis subsets. J Rheumatol 2007;34:1855-63.

36. Leidy NK. Evolving concepts in the measurement of treatment effects. Proc Am Thorac Soc 2006;3:212-7. 